\title{
O papel da respiração no cinema de horror
}

\section{Rodrigo Carreiro}

Universidade Federal do Pernambuco, Recife, Pernambuco, Brasil

\section{Resumo}

Nas últimas três décadas, a respiração tem ganhado mais destaque no som de filmes, especialmente de horror. Impulsionados por avanços tecnológicos, cineastas, atores e sound designers têm dado mais ênfase ao conteúdo não semântico da voz. Partindo de uma revisão histórica e conceitual, este artigo analisa os motivos do fenômeno, procurando refletir sobre a construção do som em filmes contemporâneos de horror, e sugerindo que a tendência estilística da respiração proeminente na banda sonora ativa um potencial sinestésico (ou cinestésico) de engajamento afetivo entre espectador e personagem, com capacidade de mobilizar outros sentidos fisiológicos.

\section{Palavras-chave}

Respiração. Horror. Voz. Sound design. Cinestesia.

\section{Introdução}

Com a cabeça parcialmente coberta por um gorro cinza, Heather Donahue (nome da atriz e também da personagem) olha diretamente para a câmera. A composição visual é confusa, desordenada: uma pequena parte do rosto ocupa a metade direita do quadro, enquanto o lado esquerdo mostra escuridão. A moça grava o vídeo numa floresta, mas nada vemos além de sua face; a localização é sugerida pelo ambiente sonoro pontilhado de insetos, que marca presença ao fundo. O rosto está próximo da câmera. É uma imagem de medo e desespero: lágrimas se acumulam na ponta no nariz e salpicam toda a face enquanto ela, antevendo a morte próxima, deixa um recado de despedida para a família. "Estou com medo de fechar os olhos, estou com medo de abri-los! Nós vamos morrer aqui! ", balbucia.

A câmera fixa enquadra o rosto de Heather durante dois minutos e 12 segundos em que dura a mais famosa sequência de A bruxa de Blair (The Blair witch project, Eduardo Sánchez 
e Daniel Myrick, 1999)․․ Mas a imagem, símbolo da cultura pop reconhecido tão instantaneamente quanto a figura de Janet Leigh no chuveiro em Psicose (Psycho, Alfred Hitchcock, 1960), não responde sozinha pelo elemento cênico de maior impacto dramático, emocional e afetivo. Esta tarefa cabe especialmente aos sons que saem da boca da atriz: as palavras, que elaboram um pungente discurso de despedida, mas sobretudo o conteúdo não semântico, pontuado por gemidos, soluços e pela respiração ofegante que sublinha toda a cena, inserindo uma sensação de horror que não cabe na citação literal da fala de Heather.

É um monólogo e tanto, mas teria a mesma eficiência em engajar afetivamente o espectador na ação dramática sem o medo e o desespero, que gradualmente saem do controle, e estão fortemente assinalados na respiração da personagem? Esta cena tornou-se tão influente que o monólogo diante da câmera se tornou um clichê dos filmes que recorrem ao formato found footage - [Rec] (Paco Plaza e Jaume Balagueró, 2007), Cloverfield-Monstro (Matt Reeves, 2008) e The Tunnel (Carlo Ledesma, 2011), por exemplo, apresentam cenas idênticas, com o mesmo uso da respiração ofegante, por personagens que sabem estar à beira da morte. Mas não são apenas os títulos vinculados a esse subgênero que apresentam a respiração dos personagens $\mathrm{da}$ ficção no primeiro plano sonoro. O monólogo de Heather Donahue simboliza uma das tendências mais salientes do sound design de filmes de horror nas últimas três décadas.

Os exemplos são múltiplos: desde filmes de grande orçamento, como mãe! (mother!, Darren Aronofsky, 2017) e Um lugar silencioso (A quiet place, John Krasinksi, 2018), a longas de baixo orçamento, como $O$ mal não espera a noite (Midsommar, Ari Aster, 2019), Hereditário (Hereditary, Ari Aster, 2018) e O homem nas trevas (Don't breathe, Fede Alvarez, 2016); passando por títulos brasileiros de baixíssimo orçamento, a exemplo de $O$ animal cordial (Gabriela Amaral Almeida, 2018) e Desaparecidos (David Schürmann 2011), e enveredando por outros gêneros fílmicos, como o melodrama Gravidade (Gravity, Alfonso Cuarón, 2013) e o thriller $O$ nome da morte (Henrique Goldman, 2018). Alguns desses filmes chegam inclusive a dar à respiração dos personagens destaque no contexto do enredo, como ocorre em Um lugar silencioso e O homem nas trevas (em ambos, qualquer pessoa que fizer barulho ao respirar, morre) e O último suspiro (Dans la brume, Daniel Roby, 2018). Nos dois últimos, personagens precisam usar máscaras especiais 
para respirar, e o som da respiração domina as bandas sonoras.

A lista apresentada é uma amostragem minúscula de um fenômeno amplo, mas serve para destacar a presença, em primeiro plano sonoro, da respiração dos personagens, com variados graus de ênfase. A antologia Histórias de além-túmulo (Ghoststories, Jeremy Syson e Ady Nyman, 2018) chega a apresentar os créditos iniciais do filme, sobre tela negra, acompanhados do som da respiração de um homem ofegante, como alguém que acabou de tomar um enorme susto. A respiração, contudo, não pertence a nenhum personagem. Quando o filme começa de fato, não há ninguém em quadro. Trata-se de uma voz sem corpo, um mero índice acústico que busca gerar tensão no espectador.

Carroll (1999) estabelece o horror como integrante de uma tríade - os outros são o thriller de suspense e o filme de mistério - de gêneros fílmicos cujos nomes "derivam do próprio afeto que pretendem provocar" (p.30). O horror, portanto, recebe o nome de uma emoção que constitui sua identidade fundamental. A condição crucial de um filme para integrar a categoria é que coloque o espectador, pelo menos em alguns momentos da trama, no estado emocional do horror, que Carroll (1999) identifica como uma soma de medo e repulsa. Esse estado emocional, por sua vez, provoca uma torrente de sensações percebidas pelo corpo do espectador (que, espera-se, espelhem as mesmas reações sentidas pelos personagens):

\begin{abstract}
Uma emoção envolve uma espécie de excitação, de perturbação ou de suspensão, fisiologicamente marcada por uma aceleração do batimento cardíaco, da respiração e de reações assemelhadas. [...] Em relação ao horror artístico, algumas das sensações - ou agitações fisicamente sentidas, ou respostas automáticas, ou sentimentos são contrações musculares, tensão, encoIhimento, tremores, recuo, entorpecimento, enregelamento, paradas momentâneas, calafrios (portanto, "frios na espinha"), paralisias, estremecimentos, náusea, um reflexo de apreensão ou um estado de alerta fisicamente incrementado (uma resposta ao perigo), talvez gritos involuntários etc. (CARROLL, 1999, p. 41).
\end{abstract}

A longa descrição de efeitos sensoriais que o filme de horror provoca no espectador - e que inclui, logicamente, a respiração como um dos mais importantes - indica que o gênero fílmico pode ser muito ativo dentre aqueles capazes de fazer o espectador experimentar o filme com o corpo inteiro, convocando outros sentidos para além da visão e da audição.

Podemos afirmar, nesse sentido, que o gênero do horror possui características narrativas adequadas acionar com eficiência um potencial sinestésico - ou cinestésico, para usar 
o neologismo criado por Sobchack (2004) - de engajamento afetivo entre espectador e personagem através dos sentidos fisiológi$\cos ^{2}$. Esse potencial, que permanecia pouco utilizado, em parte por causa das limitações tecnológicas nas áreas de gravação, edição, mixagem e reprodução sonoras, é capaz de mobilizar o tato (MARKS, 1999; BARKER, 2009) e os demais sentidos corporais, criando uma forma de escuta háptica (QUINLIVAN, 2011), ou auralidade háptica (COULTHARD, 2012), que permite ao espectador experimentar o filme com o corpo inteiro (SHAVIRO, 2015).

Seria essa a razão pela qual a respiração ganhou destaque na banda sonora de filmes, em particular do gênero horror, nas últimas três décadas? Onde podemos localizar a origem exata dessa tendência estilística? Qual a relação dela com os avanços tecnológicos nas áreas de gravação, edição, mixagem e reprodução sonora na indústria audiovisual? E, afinal, qual o motivo pelo qual algo tão prosaico, quase sempre invisível aos olhos da plateia, gere empatia entre personagens da ficção e espectadores? O que a presença da respiração destacada de personagens agrega a um filme, especialmente no gênero do horror?
Este artigo tem o objetivo de examinar essas questões. Para cumprir esse objetivo, pretendemos dividir o texto em duas seções, seguidas pelas conclusões finais. Na próxima parte, discutiremos o papel preponderante da voz no cinema clássico, bem como as inovações tecnológicas que permitiram aos realizadores ampliar, pouco a pouco, os usos não semânticos dessas gravações, para além do papel narrativo tradicional que privilegia o conteúdo semântico como condutor principal da progressão dramática. Trataremos desse tópico a partir de uma revisão teórica ampla dos escritos de pesquisadores como Bordwell (1985), Aumont (2006), Chion (2008) e Kerins (2010), entre outros.

A segunda seção mostrará como, mais recentemente, pesquisadores como Coulthard (2012), Greene (2016), Lovatt (2016), Costa (2017) e Quinlivan (2011) - esta última, autora do primeiro estudo específico sobre o papel da respiração no cinema - passaram a discutir os múltiplos usos estilísticos e a importância de elementos como timbres, texturas acústicas, sotaques e modalidades não verbais produzidas no contexto do discurso oral, incluindo gritos, sussurros, suspiros, 
gemidos, gargalhadas, choro e, claro, a respiração, para a narrativa fílmica.

A longo do texto, discutiremos os motivos pelos quais o horror tem sido um dos gêneros fílmicos que mais tem se beneficiam dessa tendência estilística. Ao discutir alguns usos da respiração em filmes de horror, como A bruxa de Blair, tentaremos demonstrar como o poder cinestésico produzido por esse elemento vocal exerce papel importante nos processos cognitivos que produzem no espectador o afeto do horror, estimulando conexões empáticas mais vigorosas entre público e personagens.

\section{Pequena arqueologia de voz e respiração no cinema}

Desde a introdução das inovações tecnológicas que permitiam a reprodução sincrônica de sons pré-gravados junto com a imagem, em 1927, a voz tem sido o componente central da banda sonora dos filmes: "todo o resto [efeitos sonoros, música] pode ser gravado e introduzido na trilha sonora depois, durante a fase da pós-produção" (CARREIRO, 2018, p. 54). Este foi o paradigma central do sistema de produção sonoro que os grandes estúdios desenvolveram em conjunto, entre os anos de 1927 e 1932, e chamaram de re-recording, termo hoje utilizado como sinônimo de mixagem (BUHLER; NEUMEYER; DEEMER, 2010). Não é à toa que os primeiros filmes sonoros eram chamados de talkies ${ }^{3}$.

Na concepção de Hollywood do "observador invisível" monocular e monaural, o som consistia essencialmente da voz humana. Até o final da década de 1930, a dublagem da voz oferecia baixa fidelidade, então a maioria dos diálogos tinha que ser capturada no momento da gravação, no som direto. Mais importante: no cinema sonoro, a voz tornou-se tão central para a banda sonora quanto a figura humana para a triIha da imagem. Assim como a construção corporal e a expressão facial, a voz individualiza e caracteriza personagens, conduz o desenvolvimento narrativo do enredo e dá acesso a fatores psicológico-causais (BORDWELL, 1985, p. 540).

A importância da gravação legível da voz orientou as inovações tecnológicas perseguidas pelo comitê formado em Hollywood para unificar procedimentos técnicos e estéticos entre os estúdios. O microfone unidirecional funciona como exemplo: foi desenvolvido em 1936, pela RCA, com o objetivo de isolar a voz dos atores dos ruídos de fundo, captados com um nível de intensidade muito mais baixo, devido à seletividade espacial da cápsula dos microfones (CARREIRO, 2018). O uso de raios ultravioleta para gravação e reprodução do 
som ajudou a reduzir sibilâncias produzidas por vozes muito agudas (BORDWELL, 1985). Além disso, a partir de 1938, Hollywood desenvolveu um protocolo de equalização sonora, a fim de uniformizar a reprodução do som em salas de projeção. O protocolo, chamado de Academy Curve, atenuava as frequências sonoras acima de $8 \mathrm{kHz}$ (mais agudas), com o propósito de permitir maior legibilidade da VOZ (CARREIRO, 2018).

Até meados dos anos 1970, a grande maioria dos filmes tinha som mixado em um único canal. Ele podia ser reproduzido nas salas de projeção por vários alto-falantes, mas todos exibiam o mesmo conteúdo. Como todos os componentes sonoros do filme disputavam lugar nesse canal, incluindo os ruídos naturais e a música, os mixadores precisavam ser seletivos. Essa seletividade, combinada à qualidade técnica incipiente dos microfones direcionais, aos métodos de edição analógicos (nos quais cada corte feito na fita ou película aumentava o ruído de fundo e reduzia a clareza sonora) e a baixa relação sinal-ruído (RSR) dos sistemas de reprodução monocanal ${ }^{4}$, é um motivo importante pelo qual a respiração, assim como os demais conteúdos não semânticos da voz, aparecem pouco e com discrição nos filmes mais antigos. Naquele contexto, a legibilidade das palavras era fundamental, pois permitia a condução do enredo sem sobressaltos.

É por essa razão que Chion (2008) afirma que o cinema é, mais do que vococêntrico (ou seja, conduzido pela voz), um meio de expressão verbocêntrico (ou seja, centrado nas palavras): "não se trata da voz dos gritos e dos gemidos, mas da voz enquanto suporte da expressão verbal" (p. 13). Para ele, o fato de a maioria maciça dos filmes ser verbocêntrica tem uma explicação cognitiva simples: o comportamento cotidiano das pessoas também o é. Se ouvimos uma massa sonora que contenha vozes em meio a outros sons, instintivamente procuraremos compreender o significado das palavras que ouvimos, e atribuir a elas um sentido lógico.

O raciocínio de Chion é referendado por Aumont (2006), que percebe no uso da voz

4 A relação sinal-ruído (RSR) consiste na diferença entre os níveis do som desejado (no caso, principalmente a voz) e o ruído de fundo. Nos anos 1940, a RSR dos sistemas de reprodução era de 50 dB (FRAYNE, 1976, p. 514). Para efeito de comparação, a taxa aumentou para 78 dB em 1975, após a introdução do sistema Dolby Stereo, que contava com uma tecnologia eletrônica de redução de ruído. Foi ampliada, ainda, para $100 \mathrm{~dB}$, depois da instituição dos sistemas multicanais digitais, como Dolby Digital, DTS e Dolby Atmos (KERINS, 2010, p. 54). Como o decibel cresce em proporção geométrica, e sabe-se que a intensidade sonora duplica a cada $10 \mathrm{~dB}$, pode-se afirmar que o som que ouvimos atualmente, nas salas de projeção, é pelo menos três vezes mais intenso do que nos anos 1970, e cinco vezes mais do que nos anos 1940-50. 
(em especial diálogos e narração) uma correlação direta com o ritmo da narrativa. Para Aumont, aliás, o cinema clássico de Hollywood - o mesmo que tinha predomínio claro da função semântica da voz - é pródigo em exemplos de filmes velozes e acelerados, pois os personagens falam sem parar, embora filmados em longos planos de câmera fixa. Aumont (2006) chama esses filmes, entre os quais um exemplo paradigmático é a comédia Jejum de amor (His girl friday, Howard Hawks, 1940), de logorreicos: "filmes em que a fala dramatizada nunca se cala" (p. 29). De certa forma, Hollywood tem feito filmes logorreicos, ou verbocêntricos, desde então, deixando em segundo plano sonoro o conteúdo não semântico da voz. Essa estética começou a sofrer mudanças em 1975.

Naquele ano, a instituição do Dolby Stereo como sistema dominante de reprodução sonora de filmes abriu espaço para que editores e mixadores pudessem trabalhar com combinações de sons de maior complexidade e variedade. O Dolby Stereo é um sistema de quatro canais (três dianteiros e um surround, reproduzido nas laterais e atrás da sala) que contra com um sistema eletrônico de redução de ruídos, para alcançar uma RSR com maior amplitude entre ruído de fundo e vozes. Essas condições permitem que a equipe de pós-produção sonora inclua um número maior de eventos sonoros, os movimente pela sala de exibição no eixo horizontal, e os reproduza com maior fidelidade acústica.

Essa nova condição tecnológica funcionou, nos anos 1970 e 1980, como uma variável importante para a ampliação da presença de ruídos naturais (e efeitos sonoros em geral) na banda sonora dos filmes. Sergi (2006) observa que a época de instituição do Dolby Stereo viu nascer a primeira geração de sound designers, entre eles Walter Murch, Alan Splet, Ben Burtt, Gary Rydstrom e Randy Thom. Todos davam maior importância ao desenvolvimento de processos mais complexos e detalhados para a criação de efeitos sonoros verossímeis, algo observado por Chion (2008, p. 122):

0 som dos ruídos aproveitou então a definição recente que the foi conferida pelo Dolby para reintroduzir nos filmes um sentimento agudo de materialidade das coisas e dos seres e favorecer um certo cinema sensorial.

O mesmo raciocínio que explica a valoração estilística dos ruídos naturais a partir dos anos 1970 deve ser aplicado ao uso da respiração e demais elementos não semânticos da voz: foi exatamente nessa época, entre o final dos anos 1970 e o início dos anos 1980, que a respiração começou a ganhar destaque narrativo e estilístico no som dos filmes. Um dos exemplos mais significativos de filmes que colocam a respiração em primeiro plano 
narrativo, dando a ela uma função expressiva e dramática crucial para o desenvolvimento do enredo, é O homem elefante (The elephant man, David Lynch, 1980), que conta a vida de John Merrick (John Hurt), um trabalhador que vive na Londres industrializada no século XIX, e tem um defeito físico que lhe deixa a respiração asmática, quase a ponto de entrar em colapso5. Greene (2016) observa que a respiração difícil de Merrick serve, no contexto do filme, para assinalar a luta persistente do personagem para sobreviver.

No gênero do horror, os sons de respiração começaram a ganhar destaque na mesma época. A sequência de abertura de Halloween (John Carpenter, 1978), um plano-sequência subjetivo de cinco minutos que mostra o primeiro assassinato cometido pelo serial killer mascarado, ainda criança ${ }^{6}$, é pontuada por sons de respiração, emparelhando os pontos de vista visual e sonoro do agressor. Carpenter, cuja contribuição criativa para o som no cinema de horror também foi importante no terreno da música ${ }^{7}$, utiliza a respiração do personagem para pontuar ritmicamente a cena, na qual o garoto espiona a irmã e seu namorado pela janela, entra na casa, pega uma faca, sobe as escadas e mata o casal.

É importante destacar que no momento culminante da sequência, quando Michael esfaqueia o casal, a mixagem de som aumenta o volume da respiração, que acelera, enfatizando a excitação e o prazer do assassino em matar. Trata-se de um excelente exemplo de uso da respiração como modo não verbal de enfatizar sensações e afetos que vão além dos sentidos da audição e da visão - é uma cena cinestésica, que antecipa a forte tendência contemporânea em explorar texturas visuais e sonoras para evocar uma experiência háptica (MARKS, 1999; QUINLIVAN, 2011).

Vale a pena lembrar, ainda, da cena de abertura de Um tiro na noite (Blow out, Brian de Palma, 1981), filmada de modo muito parecido com a descrita no parágrafo anterior: um plano-sequência subjetivo de três minutos, que assume os pontos de vista e escuta de um assassino, com uma faca, que invade uma casa onde ocorre uma festa e ataca uma

5 Uma cena do filme pode ser vista aqui: https://youtu.be/Mi42Zodnblc.

6 Veja a sequência analisada aqui: https://youtu.be/nnWw060ygG8.

7 Uma das tendências mais significativas da música no cinema de horror contemporâneo consiste na utilização massiva de drones, um estilo musical composto por notas longas, sustentadas por longos períodos de tempo, sem regularidade melódica, harmônica ou rítmica. 
mulher tomando banho ${ }^{8}$. A música - rítmica, atmosférica - está presente na maior parte da cena, mas ouvimos com careza a respiração cadenciada do agressor. O ritmo e a textura da respiração, nesse exemplo, não se alteram, o que estabelece para este filme uma personalidade muito diferente - frio, distante - do assassino. O conteúdo não semântico da voz, como podemos perceber, é importante para informar aspectos da psicologia do personagem. Sequências subjetivas pontuadas pela respiração de personagens aparecem, ainda, em filmes de horror como A hora do espanto (Fright night, Tom Holland, 1985).

Embora o uso da respiração nesses filmes não seja tão ostensivo quanto nos longas de horror contemporâneos - nos quais, em alguns casos, é tratado de modo hiper-realista (CAPELLER, 2008; SMITH, 2013) -, demarca uma distância considerável de outros trabalhos realizados apenas alguns anos antes, que foram mixados em mono e com faixa dinâmica muito mais estreita, de apenas $50 \mathrm{~dB}$. É o caso, por exemplo, de O exorcista (The exorcist, William Friedkin, 1973), no qual a adolescente Regan MacNeil (Linda Blair) passa toda a segunda metade do filme amarrada na cama, em um quarto gelado. Nesse filme, a respiração é um elemento mais visual do que sonoro. Mesmo assim, e apesar do meticuloso trabalho de sobreposição de vozes que agrega texturas ameaçadoras à psicologia do personagem, pouco conseguimos ouvir da sua respiração. A tecnologia incipiente, nesse caso, exerceu um papel limitador nessa escolha estilística da equipe de sound design.

Nesse sentido, podemos afirmar que a introdução de tecnologias de redução de ruídos e reprodução multicanal abriram caminho para a inclusão mais agressiva e sistemática de elementos cinestésicos, hápticos e sensoriais de experiência audiovisual, embora o modelo estético sonoro predominante continuasse seguindo - como ainda o faz - as convenções narrativas estabelecidas pelo sistema re-recording, consolidado em Hollywood desde 1932 (BUHLER; NEUMEYER; DEEMER, 2010). Esse modelo é construído em torno da voz (sempre posicionada no canal central), que conduz o fluxo de informações capaz de fazer o enredo avançar. Os efeitos sonoros funcionam como elemento responsável por dar verossimilhança e perspectiva espacial às cenas, enquanto a música tem a função de sinalizar a leitura emocional de cada cena, modulando os afetos que ligam personagens da ficção e audiência (CARREIRO, 2018). 
Nas décadas de 1970 e 1980, porém, como vimos, o uso ostensivo da respiração em filmes de horror surge somente nas sequências de ponto de vista subjetivo. Esse uso só seria ampliado a um novo nível de destaque narrativo a partir da disponibilização de tecnologias digitais de gravação, edição, mixagem e reprodução. Essas tecnologias permitem que a organização de sons mais delicados seja complexa e variada.

A partir de 1992, o Dolby Stereo foi substituído por uma multiplicidade de sistemas de reprodução multicanal digitais, tais como Dolby Digital, DTs, Dolby Surround 7.1 e, desde 2012, Dolby Atmos e DTs- $\mathrm{X}^{9}$, rotulados por Kerins (2010) pela sigla DSs, de Digital Surround Sound (a tradução literal seria "sons digitais que nos cercam"). Todos esses sistemas são capazes de reproduzir múltiplos sons simultâneos (de seis a 128 canais), com faixa dinâmica que chega a $100 \mathrm{~dB}$; ou seja, a diferença entre os sons mais quietos (apenas o room tone e o discreto zumbido dos alto-falantes) e os mais ruidosos (tiros, explosões) pode ir da percepção de silêncio quase absoluto ao limiar da dor ${ }^{10}$, estabelecendo uma RSR que favorece o uso do conteúdo não semântico da voz.

Aliás, as condições técnicas favorecem todos os tipos de ruídos e efeitos sonoros mínimos, delicados, que contribuem para reforçar a complexidade e a verossimilhança da narrativa. É o caso, por exemplo, do farfalhar das roupas dos personagens, um grupo discretíssimo de sons conhecido no Brasil como mumunhas, e gravados na fase de pós-produção sonora pela equipe de foley ${ }^{11}$. Como no caso da respiração, esses sons mínimos ajudam a estabelecer conexões afetivas com a plateia. O destaque que eles recebem na mixagem dos filmes contemporâneos levou Smith (2013, p. 338) a considerar o "foley hiper-detalhado" como tendência importante da estética da continuidade intensificada (BORDWELL, 2006; SMITH, 2013) - uma estética que tem como objetivo conseguir do espectador reações mais viscerais - na banda sonora.

9 Os dois últimos sistemas possuem a capacidade de codificar metadados com coordenadas espaciais nos arquivos sonoros, permitindo que eles sejam reproduzidos por alto-falantes posicionados em qualquer lugar da sala, inclusive no teto e no chão. Desde 2017, essas tecnologias também estão disponíveis para reprodução em home theaters especiais, chamados de soundbars.

10 A exposição a sons superiores a $120 \mathrm{~dB}$ pode romper o tímpano (membrana auricular) e provocar danos irreversíveis ao sistema auditivo.

11 Também conhecido no Brasil como "ruído de sala", a atividade do foley consiste em uma espécie de dublagem de ruídos, no qual uma equipe de artistas reproduz em estúdio, com a ajuda de objetos, sons resultantes da interação do homem com o ambiente: passos, tiros, aberturas de portas e janelas, toques em objetos, movimento de talheres, farfalhar de roupas etc. 
De certo modo, a afirmação de que a respiração tem sido tratada como efeito sonoro por editores, mixadores e sound designers contemporâneos é coerente. A noção é, contudo, redutora, pois presume que, ao assumir um papel que valoriza características expressivas da narrativa fílmica, a respiração estaria estilisticamente se distanciando do tratamento logorreico, dado à voz pelos editores e mixadores, para ser tratada como um componente da banda sonora mais ambíguo e complexo - o conteúdo háptico, pertencente ao reino dos sentidos. Ocorre que é impossível dissociar plenamente o conteúdo semântico da voz e suas características não verbais. As duas dimensões interagem e se complementam o tempo inteiro. As falas da personagem da menina possuída de O exorcista teriam o mesmo impacto emocional sobre a plateia sem o cuidadoso trabalho vocal de texturas, timbres e sobreposições de vozes organizado pela equipe de pós-produção sonora?

\section{Voz e cinestesia no horror contemporâneo}

Pesquisadores como Doane (1985), Carroll (1999), Quinlivan (2011) e Costa (2017) refletiram sobre usos não semânticos da voz em filmes. Eles observaram que, embora as práticas criativas dos realizadores tenham nos acostumado a pensar a voz de uma perspectiva mais utilitária, essa extensão invisível do corpo humano pode agir, e tem agido, como um poderoso elemento de ligação afetiva, mobilizando outros sentidos para além da audição, a fim de estabelecer conexões emocionais e sensoriais entre espectador e personagem. Costa (2017, p. 24), comentando um texto de 1976 escrito por Don Ihde, afirma que:

[...] a palavra falada é um centro possível para o sentido, mas a apreensão desse sentido passa pela complexa personificação dessa voz, pela presença de um corpo, com tudo que ele seja capaz de manifestar. [...] a palavra pode parecer o centro do sentido, mas no centro da palavra está o som em si, a respiração mesma. [...] Uma filosofia da escuta deveria, segundo Ihde, levar em conta o que está ao mesmo tempo entre as palavras, abaixo e acima delas, 0 que as circunda.

A maior parte dos estudos sobre a voz no cinema envolvem o conteúdo semântico de diálogos, monólogos e narrações (JAECKLE, 2013), e mobilizam a dicotomia entre fidelidade e legibilidade dos registros sonoros, proposta por James Lastra (2012). O pesquisador sugere que existem, desde a instituição do sistema de re-recording (portanto, desde a década de 1930), dois modos dominantes de apresentação de sons em meios audiovisuais - e os filmes oscilam entre ambos, aderindo mais a um ou a outro por razões estilística, econômicas ou ideológicas. O primeiro, que ele denomina de "fonográfico", privilegia a fidelidade às características acústicas presentes nos registros sonoros originais. Já o segundo, 
chamado de "telefônico", enfatiza a clareza dos aspectos semânticos. Como a maioria dos filmes está mais próxima do modelo "telefônico" (LASTRA, 2012, p. 248), é natural que Chion, Aumont e outros teóricos tenham discutido com mais atenção os aspectos semânticos da voz. Mas há exceções notáveis, das quais vamos nos ocupar nesta seção.

Uma das exceções foi Siegfried Kracauer, que dedicou parte de sua teoria a descrever maneiras de retirar dos diálogos a ênfase estabelecida pelas convenções narrativas dominantes. Os cineastas podiam destacar mais a casualidade da fala, permitir aos personagens da ficção falar sobre assuntos não relacionados à trama e, claro, enfatizar o conteúdo não semântico (CARREIRO, 2018, p. 96) - ele menciona o uso do eco em filmes de Luis Buñuel, o timbre grave da voz do monarca em Ivan o Terrível (Ivan Groznyy, Sergei Eisenstein, 1944), e o vozerio em primeiro plano nos filmes de Jacques Tati (KRACAUER, 1997, p. 109). Kracauer não menciona a respiração diretamente, mas deixa claro que a qualidade não verbal da voz pode até tornar um filme menos legível, mas também deixa-o mais afetivo e emocional.

A argumentação do crítico alemão ecoa no clássico texto de Doane (1985), uma das primeira tentativas - junto com as teorizações de Chion (2008) sobre sons acusmáticos, originários de alguma fonte sonora que não aparece em quadro - de enfatizar a importância da conexão afetiva entre voz e corpo. Para Doane (1985), a voz, e em particular suas características não semânticas, dá ao espectador consciência do seu próprio corpo, oferecendo a ele a oportunidade de experimentar (e não apenas ver/ouvir) o filme em sua plenitude, inclusive acessando a psicologia dos personagens através desse elemento narrativo invisível: "A voz demonstra o que é inacessível à imagem, o que excede o visível: a 'vida interior' do personagem. A voz é aqui a marca privilegiada da interiorização, virando o corpo “às avessas" (p.466).

Este é um dos argumentos centrais desenvolvidos por Quinlivan (2011), no primeiro estudo específico sobre o papel da respiração nos filmes. Tomando emprestado teorias sobre a voz que vêm de outras disciplinas - em particular a ontologia da respiração proposta pela socióloga Luce Irigaray, que afirma a respiração como um motivo fundamental para o estabelecimento da noção de interioridade, e mesmo de espiritualidade, do corpo humano -, Quinlivan (2011) avança a ideia de Mary Ann Doane, propondo que a respiração tem papel central na conexão afetiva e sensorial entre corpos de personagens e espectadores, numa dimensão em que filme e espectador - dois corpos, embora de naturezas diferentes, conforme 
proposto por Barker (2009) - se reúnem, gerando a experiência cinematográfica.

Traduzindo esse raciocínio para os estudos do som, Quinlivan (2011) propõe a respiração como uma espécie de contraparte sonora das ideias de visualidade háptica (MARKs, 1999), um modo de ver que enfatiza a textura tátil das imagens e o cinema cinestésico (sobsCHAK, 2004), que enfatiza uma forma de experimentar o filme com o corpo inteiro. Como elemento capaz de transcender fronteiras, como o visível e o invisível, o interior e o exterior do corpo, a respiração teria a capacidade de "orientar a percepção da experiência fílmica" (QUINLIVAN, 2011, p. 11), por interpelar afetivamente o espectador de forma contínua, através da modulação do ritmo da respiração.

O ritmo, aliás, constitui um componente particularmente importante para a experiência do horror no cinema, como enfatiza Schaub (2005), ao afirmar que a mais importante função antropológica da escuta é a estabilização do corpo no espaço, dando-lhe uma orientação tridimensional: "o olho busca e rouba, enquanto o ouvido escuta às escondidas aquilo que nos espolia. O ouvido é o órgão do medo" (p. 76).

De certa forma, a pesquisa de Quinlivan (2011) procura discutir, de uma perspectiva mais próxima dos estudos do som, as teorias propostas por Sobchack (2004) e Marks (1999), ambas intensamente visuais e pouco desenvolvidas em termos acústicos. Assim, as noções de visualidade háptica e cinestesia seriam complementadas por um modelo de escuta háptica (QUINLIVAN, 2011), que aproximaria $\mathrm{o}$ ato de ouvir à interioridade de personagens e espectadores. Este elo tornaria a experiência fílmica uma experiência não apenas cognitiva, mas emocional, afetiva e fisiológica. Desse modo, cada vez mais, a teoria contemporânea do cinema reconhece que "o cinema sempre se dirige ao espectador de maneiras multissensoriais" (ELSAESSER; HAGENER, 2018, p. 154).

É nesse contexto que Quinlivan (2011) percebe a grande importância do ato de respirar no filme de horror. Neste gênero, segundo ela, a respiração dos personagens ganha destaque generoso na banda sonora porque articula, através do afeto do horror abundante e obrigatório ao gênero (CARROLL, 1999), uma conexão significativamente mais forte, entre espectador e personagem, do que qualquer outro gênero fílmico:

Quando uma pessoa se vê diante de um momento de horror, na vida real ou diante de um filme, o evento (na forma de estímulos audiovisuais) toma dois caminhos através do cérebro, que o neurocientista Joseph E. LeDoux chama de "caminho superior" e "caminho inferior" [...]. 0 primeiro caminho busca uma compreensão consciente do evento, por meio 
de percepção e avaliação intelectual. 0 segundo conecta o momento do horror ao corpo físico (através da amígdala - um depósito de medos primais e memórias emocionais), que desencadeia uma descarga de adrenalina, respiração rápida, pressão arterial e frequência cardíaca elevadas. Essa resposta fisiológica põe todo o corpo repentinamente em estado de alerta. (WHITINGTON, 2014, p. 176).

No filme de horror, plateia e seres da ficção frequentemente entram em uma espécie de sincronia rítmica, na qual ambos experimentam o afeto do horror ao mesmo tempo, através da modulação de cenas em que as duas instâncias mantêm sincronicamente a "respiração pesada, o silêncio, a repressão e, finalmente, a liberação do grito" (QUINLIVAN, 2011, p. 23). Esse tipo de modulação narrativa do afeto do horror, de fato, aparece em literalmente centenas de filmes do gênero, como aponta Carroll (1999, p. 32): "nas obras de horror, as respostas emocionais do público, idealmente, correm paralelas às emoções dos personagens".

Sem esquecer que o grito constitui elemento central para a construção sonora do horror, é importante salientar que Quinlivan (2011) descreve com clareza, na passagem anterior, uma experiência fílmica em que convergem visualidade háptica, cinestesia e escuta háptica - ou auralidade háptica, termo alternativo proposto por Lisa Coulthard (2012), que nos parece mais preciso e adequado ao fenômeno descrito por Quinlivan (2011, p. 24):
[...] a grande importância da respiração dentro do gênero do horror se relaciona com uma expressão narrativa de natureza mais emocional está relacionada a uma expressividade mais emocional, que pode ser compreendida como uma técnica de realismo emocional amplificado.

A questão da sincronia emocional que a respiração estabelece entre espectador e personagem, através do ritmo, é um elemento crucial para explicar o motivo de tantos filmes contemporâneos estarem aproveitando a faixa dinâmica mais larga oferecida pelos sistemas reprodução digitais para explorar narrativa e cinestesicamente os sons da respiração. Um dos filmes de horror mais bem-sucedidos de 2018, Um lugar silencioso, oferece um dos exemplos mais salientes dessa técnica. O enredo induz à modulação da tensão do filme através do silêncio e da respiração dos personagens: estamos em um futuro no qual quase toda a população humana foi dizimada por monstros cegos de audição extremamente sofisticada. Os poucos sobreviventes precisam fazer o mínimo possível de ruídos para não serem localizados e mortos pelas criaturas. Por isso, andam descalços, não usam veículos e se comunicam através da linguagem de sinais.

Todo o filme é pontuado por cenas em que os personagens literalmente prendem a respiração quando percebem que há algum monstro por perto, o que faz com que o ato de respirar esteja sempre no centro das atenções dos 
personagens (e dos espectadores); ou seja, a respiração funciona, no filme, como elo afetivo fundamental entre os seres da ficção e a plateia. Além disso, por ser consequência do estado de tensão e medo provocado pelo afeto do horror (CARROLL, 1999), a respiração tem uma ligação direta com o grito - como afirma Quinlivan (2011) em passagem já citada anteriormente, a respiração pesada e a própria suspensão da respiração costumam preceder o grito, o mais importante elemento sonoro do filme de horror (CARREIRO, 2019).

No caso de Um lugar silencioso, a dupla de sound designers Eric Aadahl e Ethan Van Der Ryn usa a respiração da personagem como elemento central da modulação do suspense na cena em que a protagonista Evelyn (Emily Blunt), grávida de nove meses e com a membrana que envolve o útero já rompida (ou seja, prestes a dar a luz), pisa num prego enferrujado. Apesar da dor, ela não pode gritar para pedir socorro ou para extravasar o sofrimento, pois isso a levaria (e também o bebê) à morte. A longa sequência em que a mulher se arrasta pela casa e se abriga em uma banheira, com o rosto lavado de lágrimas e um esgar de dor, é dominada acusticamente pela respiração cadenciada e profunda ${ }^{12}$.
Outro filme de horror contemporâneo que coloca a respiração em primeiro plano é $O$ homem nas trevas. Neste caso, a própria convenção narrativa descrita por Quinlivan (2011) e explorada no exemplo anterior está colocada explicitamente no título original do filme (em tradução literal, "Não respire"). Na trama, três jovens arrombam a casa de um senhor cego de meia idade (Stephen Lang) para roubá-lo, mas descobrem que o homem possui uma casa cheia de armadilhas e, armado, os persegue. Em vários momentos, os ladrões e a vítima ficam frente a frente; nesses momentos, os jovens prendem a respiração para não serem descobertos ${ }^{13}$. Em outras cenas, eles revelam sua presença inadvertidamente, por não conseguirem prender a respiração por tempo suficiente, desempenhando uma convenção de gênero que Lovatt (2016, p. 169) descreve assim:

[...] no gênero do horror e no [subgênero do] slasher, nos momentos de maior tensão, (normalmente mulheres) personagens prendem a respiração para evitar serem descobertas pelo assassino: a respiração em si se torna uma marca audível da vulnerabilidade da vítima, tanto quanto as exalações agressivas do matador evocam sua proximidade física e a ameaça iminente que ele representa. 
A mesma convenção pode ser vista na sequência final de $[R e c]$. Na cena em questão, uma repórter e um cinegrafista entram na cobertura de um prédio de Barcelona, descobrem uma criatura monstruosa no local, e tentam prender a respiração para não serem descobertos (mas o ato de respirar os denuncia). A estilística de documentário empregada na filmagem reforça ainda mais o paralelo fisiológico entre as emoções dos personagens e do espectador - e a cena, como nos filmes anteriores, culmina com uma sinfonia de gritos ${ }^{14}$.

Em Hereditário (2018), o diretor e roteirista Ari Aster usa a respiração de Peter (Alex Wolff), em primeiro plano sonoro, para assinalar fisiologicamente o peso emocional da tragédia que se abate sobre a família Graham, com a morte da irmã mais nova, num acidente automobilístico provocado pelo personagem masculino. De forma semelhante, em O mal não espera a noite (2019), o mesmo Aster utiliza a respiração cadenciada da atormentada estudante Dani (Florence Pugh) como um acompanhamento quase musical, para modular a desorientação e o horror físico que a personagem experimenta, em particular na sequência final, ao ver o ex-namorado ser queimado vivo. O diretor dos dois filmes confirmou, em entrevista recente, a intencionalidade do uso da respiração dos personagens como elemento estilístico capaz de gerar tensão e ansiedade na plateia ${ }^{15}$.

\section{Considerações finais}

A respiração, portanto, possui uma função narrativa importante nos filmes de horror contemporâneos: o reforço ou estabelecimento de uma empatia sensório-afetiva entre personagem e espectador. Essa empatia é muitas vezes modulada pelo ritmo dessa respiração. Nesse sentido, vale a pena lembrar o que Schafer (2001) escreveu sobre a conexão existente entre o ritmo da respiração e o aparelho sensório do ser humano - quando estamos nos sentindo bem, respiramos mais lentamente; se algo vai errado, respiramos mais rápido. Schafer (2001) enfatiza a importância da respiração no estabelecimento de ritmos e métricas internas nas artes, e diz se surpreender pelo fato de poucos críticos literários terem escrito sobre a importância da respiração (do autor, e também do personagem) no fluxo narrativo.

Podemos dizer o mesmo sobre as produções audiovisuais. Talvez por causa do caráter não semântico, ou talvez por ser algo tão delicado

\footnotetext{
14 A sequência analisada está aqui: https://youtu.be/qbqt884tkLs.

15 A entrevista está aqui: https://youtu.be/aPGaPTdno10?t=2814 .
} 
e banal, a respiração parece não ter ainda chamado apropriadamente a atenção dos pesquisadores para o papel importante que exerce na criação e na modulação dos ritmos que conectam personagens e espectadores. De todo modo, ainda que o papel da respiração nos filmes ainda seja pouco discutido, não há dúvida de que esse elemento acústico vem ganhando destaque na teoria do cinema nos últimos anos, como reconhecem Elsaesser e Hagener (2018, p. 155).

Elsaesser e Hagener (2018) enfatizam, ainda, a tendência de teóricos contemporâneos muitos dos quais citados neste artigo, como Shaviro (2015), Barker (2009), Sobchack (2004) e Marks (1999) - a pensar o corpo inteiro como receptáculo afetivo da experiência cinematográfica, que envolveria os cinco sentidos, e não apenas a visão e a audição. Essa tendência conceitual é compatível com a proeminência crescente da respiração na banda sonora dos filmes, algo percebido por Lovatt (2016, p. 170):

Em momentos-chave do enredo, a ausência de música pode ser combinada com lacunas no diálogo para criar espaço dentro da ecologia acústica do filme, a fim de permitir momentos de intimidade sensorial entre o espectador e os seres na tela. Nessas cenas, o som da respiração dos personagens pode ser ouvido alto na mixagem, criando a impressão de proximidade espacial e alinhamento afetivo, e dando a impressão de que nós [espectadores] também estamos envolvidos na ação fílmica.
A partir dos estudos de Quinlivan (2011), Coulthard (2012), Greene (2016), Lovatt (2016) e Costa (2017), é possível seguir os passos de Carroll (1999) e afirmar que a respiração constitui, atualmente, um dos elementos estilísticos mais eficientes na tarefa de convocar o espectador a experimentar o filme de perspectivas afetivas (e não apenas sonora) similares ou próximas àquelas ocupadas pelos personagens da ficção. Portanto, a respiração proeminente contribui de modo efetivo para que a plateia experimente cinestesicamente o filme, tendo o corpo inteiro afetado pelo conteúdo ficcional. Em última instância, a respiração materializa uma forma háptica de o espectador responder ao filme com o corpo. E se o ato de respirar é importante para o cinema contemporâneo, podemos reiterar que é ainda mais central para o cinema de horror.

\section{Referências}

ASTER, Ari. Ari Aster on Midsommar, cathartic endings, the director's cut, and his favorite films. 2019 (1:02:06). Disponível em: https://youtu.be/aPGaPTdno10?t=2814. Acesso em: 25 set. 2019.

AUMONT, Jacques. O cinema e a encenação. Lisboa: Texto \& Grafia, 2006.

BARKER, Jennifer. The tactile eye: touch and the cinematic experience. Berkeley: University of California Press, 2009.

BORDWELL, David. The introduction of sound. In: BORDWELL, David; THOMPSON, 
Kristin; STEIGER, Janet (Org.). The classical Hollywood cinema: film style \& mode of production to 1960. New York: Columbia University Press, 1985, p. 536-547.

BORDWELL, David. The way Hollywood Tells it: story and style in modern movies. Los Angeles: University of California Press, 2006.

BUHLER, James; NEUMEYER, David; DEEMER, Rob. Hearing the movies: music and sound in film history. New York: Oxford University Press, 2010.

CAPELLER, Ivan. Raios e trovões: hiperrealismo e sound design no cinema contemporâneo. $\mathbf{O}$ som no cinema. Rio de Janeiro: Caixa Cultural, 2008. p. 65-70. (Catálogo).

CARREIRO, Rodrigo. A história do som dos filmes. In: CARREIRO, Rodrigo (Org.). 0 som do filme: uma introdução. Curitiba: Editora da UFPR; Editora da UFPE, 2018. p. 36-86.

Por uma teoria do som no cinema de horror: padrões recorrentes de estilo. Ícone, Recife (UFPE), v. 17, n. 3, p. 251-269, 2019.

CARROLL, Noël. A filosofia do horror ou paradoxos do coração. Campinas: Papirus, 1999.

CHION, Michel. A audiovisão: som e imagem no cinema. Lisboa: Texto \& Grafia, 2008.

COSTA, Fernando Morais. Teorias sobre voz nas décadas de 1960 e 1970 e cinema contemporâneo. Novos Olhares, v. 6, n. 2, p. 22-29, ago. 2017.

COULTHARD, Lisa. Haptic aurality: resonance, listening and Michael Haneke. Film-Philosophy, v.16, n. 1, 2012, p. 16-29.
DOANE, Mary Ann. A voz no cinema: a articulação de corpo e espaço. In: XAVIER, Ismail (Org.). A experiência do cinema. Rio de Janeiro: Edições Graal, 1983.

ELSAESSER, Thomas; HAGENER, Malte.

Teoria do cinema: uma introdução através dos sentidos. Campinas: Papirus, 2018.

FRAYNE, John G. Motion Picture sound recording: a capsule history. Journal of the Audio Engeneering Society, n. 24, v. 6, p. 512-516, 1976.

GREENE, Liz. The labour of breath: performing and designing breath in cinema. Music, sound, and the moving image, v. 10, n. 2, 2016, p. 109-133.

JAECKLE, Jeff. Film dialogue. New York: Columbia University Press, 2013.

KERINS, Mark. Beyond Dolby (Stereo):

Cinema in the digital sound age. Bloomington: Indiana University Press, 2010.

KRACAUER, Siegfried. Theory of film.

New Jersey: Princeton University Press, 1997.

LASTRA, James. Fidelity versus intelligibility. In: STERNE, Jonathan (Org). The sound studies reader. New York: Routledge, 2012. p. 248-254.

LOVATT, Philippa. Breathing bodies: sounding subjectivity in the war film. Music, sound, and the moving image, v. 10, n. 2, p. 167-188, 2016.

MARKS, Laura U. The Skin of the film: intercultural cinema, embodiment, and the senses. Durham: Duke University Press, 1999.

QUINLIVAN, Davina. The place of breath in cinema. Edinburgh: Edinburgh University Press, 2011. 
SCHAFER, Murray. A afinação do mundo.

São Paulo: Editora Unesp, 2001.

SCHAUB, Mirjam. Bilder aus dem off:

zum philosophischen stand der kinotheorie.

Weimar: VDG, 2005.

SERGI, Gianluca. In defense of vulgarity.

Scope, v. 5, n.1, p. 1-13, 2006. Disponível em: http://www.scope.nottingham.ac.uk/article. php?id=129\&issue=5. Acesso em: 29 abr. 2019.

SHAVIRO, Steven. 0 corpo cinemático. São Paulo: Editora Paulus, 2015.

SMITH, Jeff. The sound of intensified continuity. In: RICHARDSON, John; GORBMAN, Claudia; VERNALLIS, Carol (Org.). The Oxford Handbook of new audiovisual aesthetics. New York: Oxford University Press, 2013. p. 331-356.

SOBCHACK, Vivian. Carnal thoughts: embodiment and moving image culture. Berkeley: University of California Press, 2004.

WHITINGTON, William. Horror sound design. In: BENSHOFF, Harry M. (Org.). A companion to the horror film. West Sussex: Wiley Blackwell, 2014. p.168-185.

\section{Filmografia}

[REC]. Direção: Paco Plaza e Jaume Balagueró. Produtora: Filmax International. Espanha, 2007. 1 Blu-Ray (78 min).

A BRUXA DE BLAIR (The Blair witch project). Direção: Eduardo Sánchez e Daniel Myrick. Produtora: Haxan Films. Estados Unidos, 1999. I DVD (81 min).

A HORA DO ESPANTO (Fright night). Direção: Tom Holland. Produtora: Columbia Pictures. Estados Unidos, 1985. 1 Blu-Ray (106 min).
CLOVERFIELD - Monstro. Direção: Matt Reeves. Produtora: Bad Robot Productions. Estados Unidos, 2008. 1 Blu-Ray (85 min).

DESAPARECIDOS. Direção: David

Schürmann. Produtora: Schürmann Filmes.

Brasil, 2011. 1 DVD (73 min).

GRAVIDADE (Gravity). Direção: Alfonso Cuarón. Produtora: Heyday Films. Estados Unidos/México, 2013. 1 Blu-Ray (91 min).

HALLOWEEN. Direção: John Carpenter. Produtora: Compass International Pictures. Estados Unidos, 1978. 1 DVD (91 min).

HEREDITÁRIO (Hereditary). Direção: Ari Aster. Produtora: A24. Estados Unidos, 2018. 1 Blu-Ray (127 min).

HISTÓRIAS DE ALÉM-TÚMULO (Ghost stories). Direção: Jeremy Syson e Ady Nyman. Altitude Films. Inglaterra, 2018. I DVD (98 min).

IVAN O TERRIVEL (Ivan Groznyy). Direção: Sergei Eisenstein. Produtora: Mosfilm. União Soviética, 1944. I DVD (103 min).

JEJUM DE AMOR (His girl friday). Direção: Howard Hawks. Produtora: Columbia Pictures. Estados Unidos, 1940. 1 DVD (92 min).

MÃE! (mother!). Direção: Darren Aronofsky. Produtora: Paramount Pictures. Estados Unidos, 2017. 1 Blu-Ray (115 min).

O ANIMAL CORDIAL. Direção: Gabriela Amaral Almeida. Produtora: RT Features. Brasil, 2018. Video on demand (Canal Brasil, $98 \mathrm{~min})$.

O EXORCISTA (The exorcist). Direção: William Friedkin. Produtora: Hoya Productions. Estados Unidos, 1973. 1 Blu-Ray (121 min). 
O HOMEM ELEFANTE (The elephant man). Direção: David Lynch. Produtora: Brooksfilms. Estados Unidos/Inglaterra, 1980. I DVD (124 min).

O HOMEM NAS TREVAS (Don't breathe). Direção: Fede Alvarez. Produtora: Ghost House Pictures. Estados Unidos, 2016. Video on demand (Netflix, $88 \mathrm{~min}$ ).

O MAL NÃO ESPERA A NOITE (Midsommar). Direção: Ari Aster. Produtora: A24. Estados Unidos, 2019. 1 Blu-Ray (147 min).

O NOME DA MORTE. Direção: Henrique Goldman. Produtora: Globo Filmes. Brasil, 2018. 1 DVD (98 min).

O ÚLTIMO SUSPIRO (Dans la brume). Direção: Daniel Roby. Produtora: Quad Productions. França, 2018. 1 Blu-Ray (89 min).
PSICOSE (Psycho). Direção: Alfred Hitchcock. Produtora: Universal Pictures. Estados Unidos, 1960. I Blu-Ray (109 min).

THE TUNNEL. Direção: Carlo Ledesma.

Produtora: Distracted Media. Austrália, 2011.

Video on Demand (90 min).

UM LUGAR SILENCIOSO (A quiet place). Direção: John Krasinksi. Produtora: Platinum Dunes. Estados Unidos, 2018. 1 Blu-Ray (91 min).

UM TIRO NA NOITE (Blow out). Direção: Brian de Palma. Produtora: Filmways. Estados Unidos, 1981. I DVD (108 min).

\section{Informações sobre 0 artigo}




\section{The role of breath in horror film}

\section{Abstract}

In the last three decades, breathing has gained more prominence in film sound, especially on the horror genre. Driven by technological advances, filmmakers, actors and sound designers have placed more emphasis on the non-semantic content of the voice. This article analyzes the reasons for this phenomenon. Based on historical and conceptual review of the subject, we sought to reflect on the construction of sound in contemporary horror films, and to suggest that the stylistic tendency of the prominent breathing in the soundtrack activates a synesthetic potential of affective engagement between spectator and character, with the ability to mobilize other physiological senses.

\section{Keywords}

Breath. Horror. Voice. Sound design. Cinesthesia.

\section{El papel del aliento en el cine de terror}

\section{Resumen}

En las últimas tres décadas, la respiración ha ganado más destaque en el sonido de las películas, especialmente de horror. Impulsados por avances tecnológicos, cineastas, actores y diseñadores de sonido han dado más énfasis al contenido no semántico de la voz. Este artículo analiza los motivos de este fenómeno. Con base en la revisión histórica y conceptual del asunto, tratamos de reflexionar sobre la construcción del sonido en películas contemporáneas de horror, y sugerir que la tendencia estilística de la respiración prominente en la banda sonora activa un potencial sinestesico de compromiso afectivo entre espectador y personaje, con capacidad de movilizar otros sentidos fisiológicos.

\section{Palabras clave}

Aliento. Horror. Voz. Diseño de sonido. Cinestesia.

\section{Rodrigo Carreiro}

Doutor pelo Programa de Pós-Graduação em Comunicação da Universidade Federal de Pernambuco.

Professor do Departamento de Comunicação da Universidade Federal de Pernambuco.

Universidade Federal do Pernambuco,

Recife, Pernambuco, Brasil.

E-mail: rcarreiro@gmail.com

ORCID: https://orcid.org/0000-0003-3087-9557 